\title{
Impact of Low Calcium Fly Ash on Steel Corrosion Rate and Concrete- Steel Interface
}

\author{
Hui $\mathrm{Xu}^{1,2, *}$, Zhanqing $\mathrm{Chen}^{1,2}, \mathrm{Bi} \mathrm{Xu}^{3}$ and $\mathrm{Dan} \mathrm{Ma}^{1,2}$ \\ ${ }^{I}$ State Key Laboratory for Geomechanics \& Deep Underground Engineering, China University of Mining \& Technology, \\ Xuzhou 221116, China \\ ${ }^{2}$ School of Mechanics \& Civil Engineering, China University of Mining \& Technology, Xuzhou 221008, China \\ ${ }^{3}$ CCCC Tianjin Dredging Co.,Ltd, Tianjin 300450, China
}

\begin{abstract}
The use of fly ash is not only in harmony with the concept of sustainable development, but also beneficial to some mechanical properties of concrete. This paper discusses steel corrosion rate time-changing law in concrete with different replacing ratios of low calcium fly ash $(10 \% \sim 30 \%)$ and the microcosmic characteristic of concrete-steel interface. The steel corrosion rate was tested by linear polarization and weak polarization for corrosion monitoring in man-made climate environment, the microcosmic characteristic of concrete-steel interface was observed by Electronic Microscope and Scanning Electron Microscope. The experimental results showed that addition of 10\% 30\% fly ash increased the ability of concrete to resist steel corrosion, and the concrete with $20 \%$ replacement ratio of fly ash had the least corrosion layer thickness. The microscopic and microcosmic results further verified and explained the point of view. The analytical results of present work showed that the addition of fly ash in concrete had dual effects: (a) reducing concrete porosity and (b) improving the concrete-steel interface structure. Therefore, the replacement ratios of 10\% 30\% low calcium fly ash can be effectively used in structural concrete.
\end{abstract}

Keywords: Reinforced concrete, fly ash, corrosion rate, interface.

\section{INTRODUCTION}

Corrosion of rebar in concrete has always been recognized as a major problem in the durability of reinforced concrete structures $[1,2]$. Steel corrosion in concrete results in the steel cross-sectional area decreasing, concrete compressive strength falling and bonding capability between steel and concrete playing down, concrete cracking and ultimate structural failure [3-5]. In the natural environment, steel corrosion in concrete is a very slow process, so it is difficult to establish the corrosion rate model. The rust productions of steel corrosion in concrete bring volume dilatancy to concrete-steel interface, then the tensile stress increases in the concrete cover, which results in concrete cracking. Therefore, the corrosion process of steel reinforcement is also corrosion layer developing process, which is formed in concrete-steel interface, this formation process and distribution characteristics determine the steel corrosion rate [6].

There are many factors that affect the rebar corrosion rate, including environment factors and concrete material factors [7]. The utilization of fly ash as partial replacement of cement, not only reduces environment pollution, but also improves partial performances of concrete. Siddique [8] reported that the use of fly ash as a partial replacement

\footnotetext{
*Address correspondence to this author at the State Key Laboratory for Geomechanics and Deep Underground Engineering, China University of Mining and Technology, Xuzhou 221008, P. R. China; Tel: +86-15852476973; E-mail: xuhui_cumt@126.com
}

of cement decreased its 28-day compressive, tensile, and flexural strength, modulus of elasticity, and abrasion resistance of the concrete, but all these properties were improved at the ages of 91 days and 365 days. Poon [9] studied the effects of fly ash mixing into high strength concrete and concluded that the high strength concrete with $45 \%$ fly ash had lower heat of hydration and chloride diffusivity. The test results also showed that the lower the water/binder(w/b) ratios are, the higher of the fly ash contribute to strength. Jiang [10] studied the effect of the activator on the durability of fly ash concrete, and the results showed that the concrete with an activator had good carbonation and corrosion resistance of steel reinforcement. Saraswathy [11] adopted chemical method to activate the fly ash, and the studies showed that adding 20\% 30\% replacement ratios of activated fly ash into concrete improved the strength and corrosion-resistance.

Based on the previous studies on durability of fly ash concrete, this paper aimed to obtain the effect of replacing ratio of low calcium fly ash(10\% 30\%) on the steel corrosion rate in concrete. The concrete mixtures were prepared at the $w / b$ ratio of 0.54 . Low-calcium fly ash was used in the proportions of $0 \%, 10 \%, 20 \%$ and $30 \%$ of the total mass of cementitious materials. Linear polarization and weak polarization monitoring corrosion process were applied to evaluate the steel corrosion rate. Microscopic observation and scanning electron microscope(SEM) methods were used to analyze the concrete-steel interface varieties induced by steel corrosion. 


\section{EXPERIMENTAL}

\subsection{Materials}

Ordinary Portland Cement (OPC) and low calcium fly ash were used as cementitious materials. The type of OPC is 325\# and the fly ash was obtained from Tong Shan Plant of Xuzhou. Natural sand and crushed granite were used as fine and coarse aggregates, respectively. The physical composition of fly ash includes crystal mineral, such as quartz, mullite, feldspar(a little), and other non-crystalline minerals, and the chemical components are presented in Table $\mathbf{1 .}$

The 28-day target compressive strength of ordinary Portland cement concrete was $25 \mathrm{MP}$, and the corresponding w/b was 0.54 . Fly ash was used in the proportions of $0 \%, 10 \%$, $20 \%$ and $30 \%$ of the total cementitious materials. Concrete mixes with fly ash content of $10 \%, 20 \%$ and $30 \%$ by weight of cementitious materials were designated as FA10, FA20 and FA30, respectively, whereas concrete without fly ash was designated as OPC. The mix proportions of concretes and the corresponding tested compressive strength are shown in Table 2.

\subsection{Specimen Preparation}

The $460 \times 120 \times 100$ concrete specimens were cast for test, a HRB335 steel bar with $16 \mathrm{~mm}$ diameter and a stainless steel bar with $14 \mathrm{~mm}$ diameter were set in concrete, with each cover thickness of $20 \mathrm{~mm}$, as is shown in Fig. (1). In the end of the exposed area of steel, wires were welded to connect the equipment. In order to speed up steel corrosion process, the concrete was mixed with $6 \% \mathrm{NaCl}$. Cube specimens were also prepared to measure compressive strength of concrete. All specimens were cured at $20 \pm 5^{0} \mathrm{C}$ and $100 \%$ relative humidity for 28 days prior to exposure to test environment.

\subsection{Rebar Corrosion Rate Test}

The laboratory environment was set to $20 \pm 5^{\circ} \mathrm{C}$ temperature, $70 \% \pm 5 \%$ relative humidity and $20 \% \pm 3 \% \quad \mathrm{CO}_{2}$ concentration. After one week in the laboratory (when internal temperature and humidity of concrete was consistent with the environmental), the measurement was started. Electrochemical testing system, with linear polarization and weak polarization method, was used for corrosion monitoring. It can measure the instantaneous corrosion rate of the material in succession. According to metal corrosion theory, corrosion current density was measured to substitute corrosion rate. Saturated $\mathrm{CuSO}_{4}$ solution, stainless steel rebar and ordinary steel rebar were used as the reference electrode, auxiliary electrode and work electrode, respectively.

\subsection{Microscopic Test}

Taking protective layer as the above direction, left longitudinal rib of the rebar as the start point, along the clockwise, the area around the steel was divided into 12 parts, as is shown in Fig. (2). The cross-sectional was taken using cutting machine, and the observation plane was made smooth using polishing machine and sand paper, as is shown in Fig. (3). KH-3000V/KH-3000VD HI-SCOPE Advanced Digital Video Microscope Measure System was used for microscopic observation. The instrument has two amplificatory lens, one is high and the other is low. It can observe and collect color photographs by connecting to the computers.

Table 1. Chemical Composition of Fly Ash

\begin{tabular}{|c|c|c|c|c|c|c|c|}
\hline Chemical Composition & SiO2 & $\mathbf{A l 2 O 3}$ & Fe2O3 & CaO & MgO & SO3 & Loss \\
\hline \hline Range $(\%)$ & $20 \sim 62$ & $10 \sim 40$ & $3 \sim 19$ & $1 \sim 45$ & $0.2 \sim 5$ & $0.02 \sim 4$ & $0.6 \sim 51$ \\
\hline
\end{tabular}

Table 2. Mixture Proportions of Concrete with Different Replacement Ratios of Fly Ash

\begin{tabular}{|c|c|c|c|c|c|c|}
\hline Number & FA\% & $\mathbf{C}(\mathbf{k g} / \mathbf{m} 3)$ & F+C(kg/m3) & Sand(kg/m3) & Gravel(kg/m3) & Tested Compressive Strength(MP) \\
\hline \hline OPC & 0 & 312.5 & 312.5 & 525 & 968.8 & 28.6 \\
\hline FA10 & 10 & 283.5 & 324.1 & 515.2 & 968.8 & 27.5 \\
\hline FA20 & 20 & 250 & 331.3 & 506.1 & 968.8 & 25.8 \\
\hline FA30 & 25 & 234.4 & 336.0 & 501.8 & 968.8 & 25.2 \\
\hline
\end{tabular}

Note: $\mathrm{FA} \%$ is the replacement ratio of fly ash in concrete, $\mathrm{C}$ is weight of cement in concrete unit, $\mathrm{F}+\mathrm{C}$ is total weight of fly ash and cement in concrete unit.
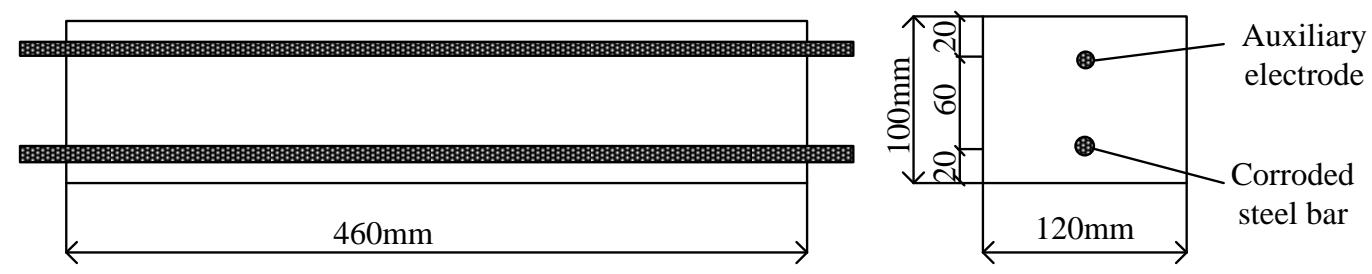

Fig. (1). Samples design. 


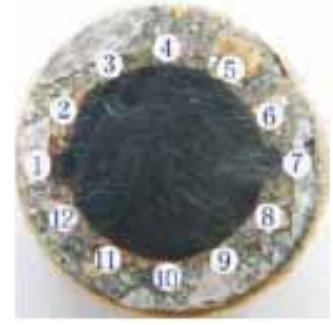

Fig. (2). Measured point label for microscopic test.

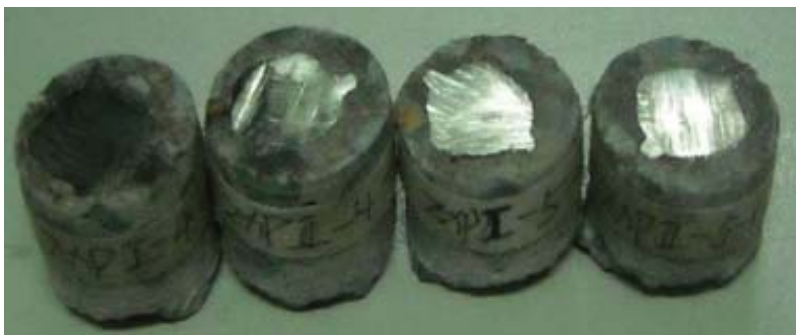

Fig. (3). Samples after cutting processing.

In order to observe the time-changing characteristic of concrete-steel interface more clearly, S250-MK3 scanning electron microscope (SEM) was used for microcosmic observation. According to the requirement of the equipment, the specimens were processed into small pieces, with $2.5 \mathrm{~cm}$ diameter and $1.0 \mathrm{~cm}$ height, as is shown in Fig. (3).

\section{RESULTS AND DISCUSSION}

\subsection{Corrosion Rate}

The effects of four replacement ratios of fly ash on corrosion rate are given in Fig. (4). It shows that in the same external environment, with an increase in corrosion time, the rebar corrosion rates of all the samples have similar variation curves: rapid decline in early stage-longer stationary phase in metaphase stage-rising in late stage.

At the beginning, with an increase in fly ash, the rebar corrosion rate was decreasing. In the decline phase, the slump speed of OPC was greater than the others. Steel corro- sion rates in OPC achieved the steady state in about one month, and the corrosion rate was about 0.53 times the initial corrosion rate. Steel corrosion rates in FA10, FA20 and FA30 achieved the steady state in about four months, and the corrosion rates were about $0.51,0.36$ and 0.32 times the initial rates. When the corrosion time reached about 8 months, the OPC appeared visible cracks and the corrosion rates in OPC began to rise rapidly, because the cracks appearance accelerates the steel corrosion. However, FA10, FA20 and FA30 had no visible crack.

\subsection{Concrete-Steel Interface}

According to the results of corrosion rate discussed above, the reinforced concrete samples were cut for 4 times. The first cutting was done after one week corrosion in the lab when the corrosion was inchoate. The second cutting was done after one month of corrosion in the lab when the corrosion rate was decreasing. The third cutting was done after five months of corrosion in the lab when the corrosion rate was steady, and the fourth cutting was done after nine months of corrosion in the lab when the corrosion rate was rising again, as is shown in Fig. (4).

Fig. (5a-d) illustrate the sub-microstructures of concretesteel interface taken from OPC, FA10, FA20 and FA30 after one week of corrosion. It can be seen that early in the corrosion stage, the corrosion layers of all the specimens were small, because oxide layers that were formed and maintained on the surfaces of steel bars had not been completely destroyed. The corrosion layer thickness of OPC, FA10, FA20 and FA30 were $50 \mu \mathrm{m}, 40 \mu \mathrm{m}, 22 \mu \mathrm{m}$ and $20 \mu \mathrm{m}$, respectively.

Fig. (6a and b) present the amplified 600 multiples SEM photographs of concrete- steel interface taken from OPC and FA20, and Fig. (6c and d) illustrate the corresponding amplified 1000 multiples SEM photographs. The results reveal that in initial corrosion period, FA20 had a denser interface, and the particles in the interface were more tiny and even.

Fig. (7a-d) illustrate the sub-microstructures of concretesteel interface taken from OPC, FA10, FA20 and FA30 after one month corrosion. It can be seen that the corrosion layers of all the specimens were thicker, and the corrosion layer

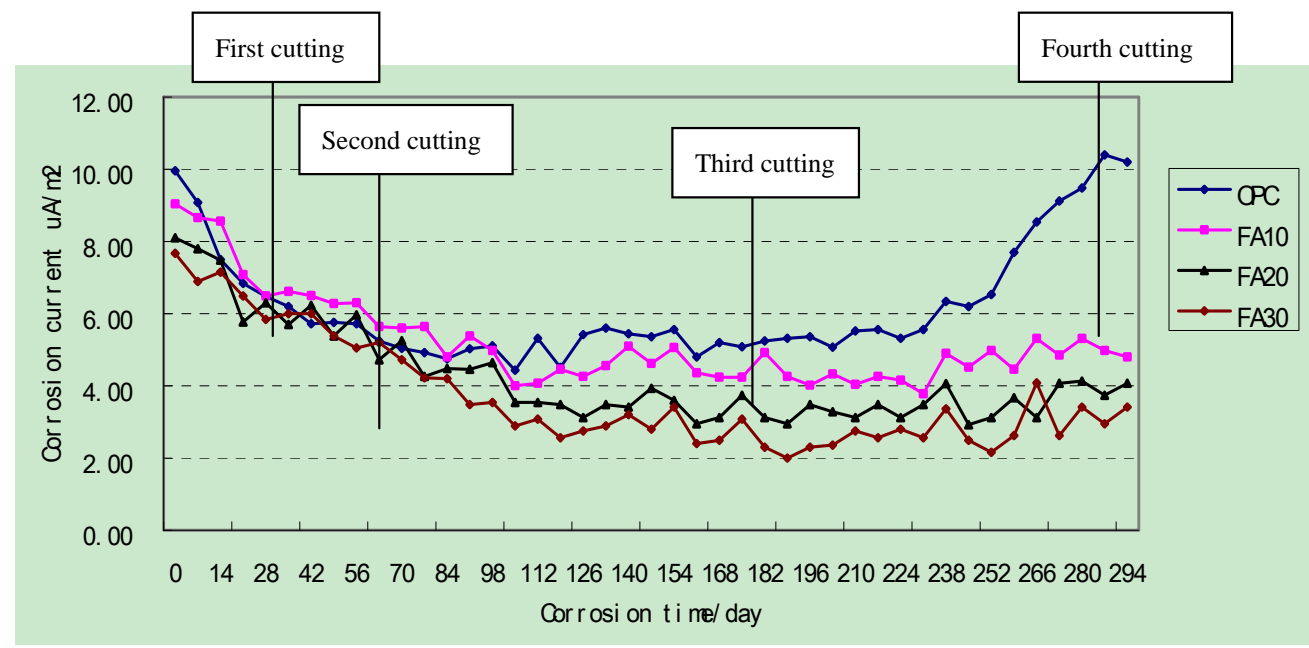

Fig. (4). Corrosion current density of steel bars and cutting time design. 


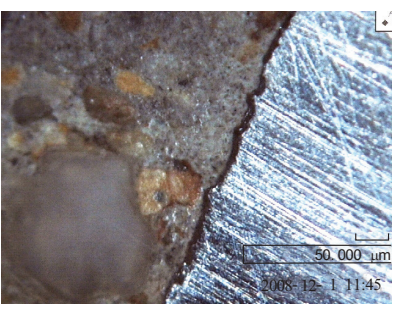

(a) OPC (Test point 5)

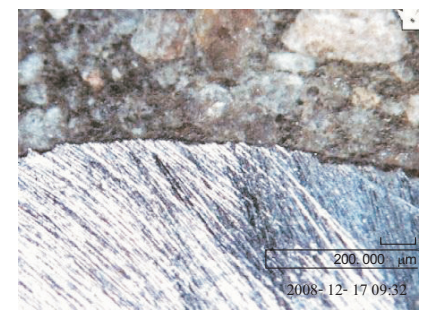

(b) FA10 (Test point 4)

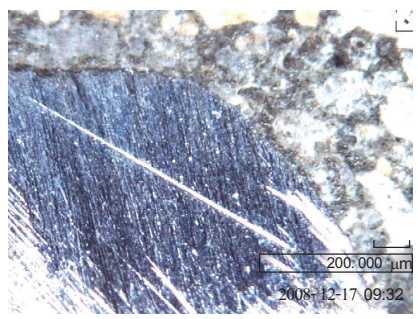

(c) FA20 (Test point 3)

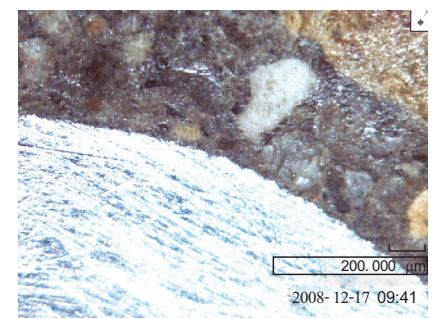

(d) FA30 (Test point 3)

Fig. (5). Sub-microstructure of concrete-steel interface after one week corrosion.

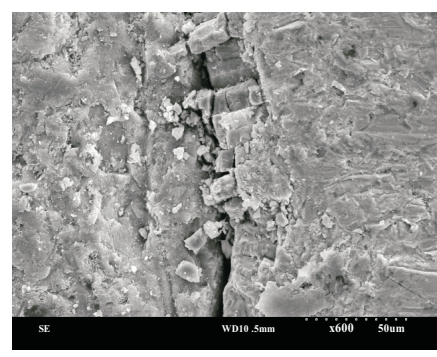

(a) $\mathrm{OPC}(600 \times)$

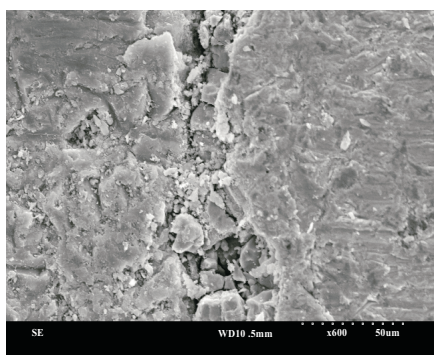

(b) FA20 (600×)

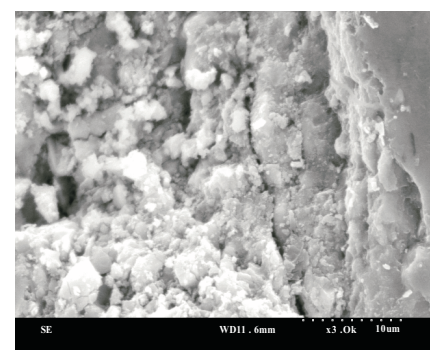

(c) OPC $(1000 \times)$

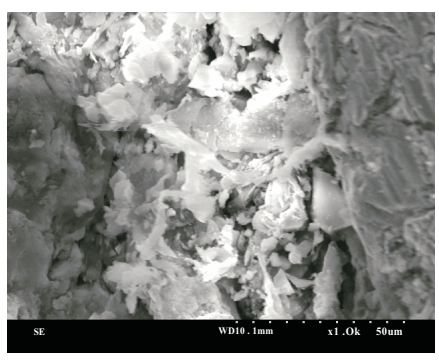

(d) FA20 (1000×)

Fig. (6). Microscopic structure of concrete-steel interface after one week corrosion.

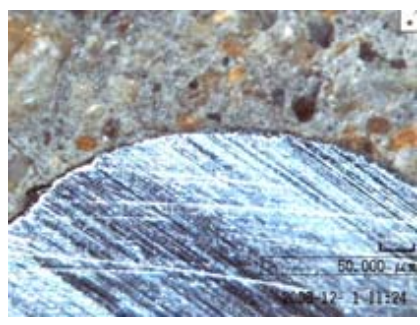

(a)OPC (Test point 4)

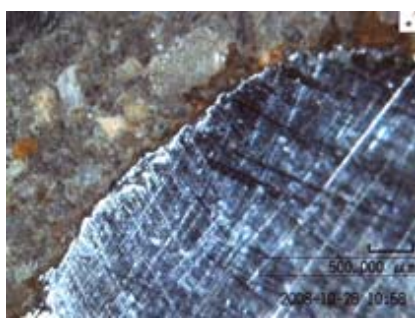

(b)FA10 (Test point 3)

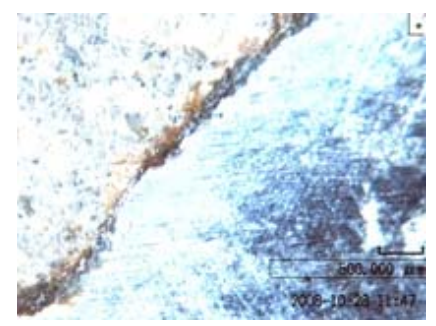

(c)FA20 (Test point 3)

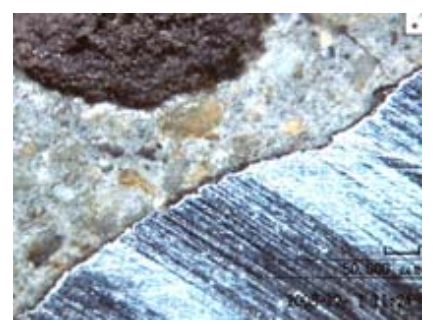

(d)FA30 (Test point 3)

Fig. (7). Sub-microstructure of concrete-steel interface after one month corrosion.

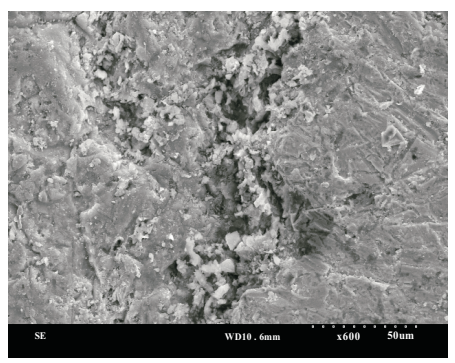

(a) $\mathrm{OPC}(600 \times)$

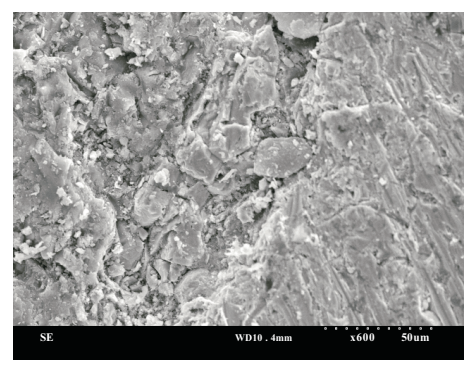

(b) FA20 $(600 \times)$

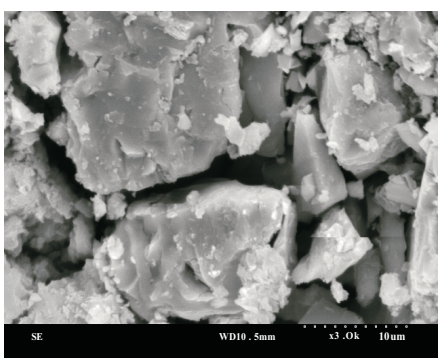

(c) $\mathrm{OPC}(3000 \times)$

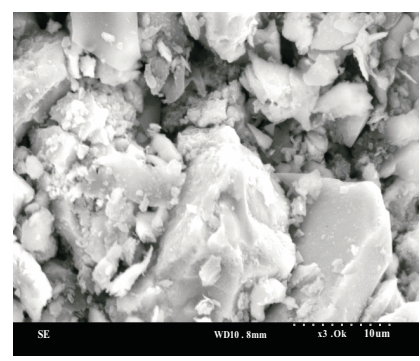

(d) FA20 (3000×)

Fig. (8). Microscopic structure of concrete-steel interface after one month corrosion.

thickness of OPC, FA10, FA20 and FA30 were $62 \mu \mathrm{m}, 54 \mu \mathrm{m}$, $50 \mu \mathrm{m}$ and $48 \mu \mathrm{m}$, respectively. The differences of corrosion layer thickness between the samples were shortening. Fig. (8a and b) present the amplified 600 multiples SEM photographs of concrete-steel interface taken from OPC and FA20. Fig. (8c and d) illustrate the corresponding amplified 3000 multiples SEM photographs. It can be seen that the concrete-steel interfaces were both made of loose and big block, and the particles in the interface were more tiny and even.

Fig. (9a-d) illustrate the sub-microstructures of reinforced-concrete interface taken from OPC, FA10, FA20 and FA30 after five months corrosion. It can be seen that the corrosion layers of all the samples were thicker, and the thickness of OPC, FA10, FA20 and FA30 were $123 \mu \mathrm{m}, 118 \mu \mathrm{m}$, $106 \mu \mathrm{m}$ and $103 \mu \mathrm{m}$, respectively. It is apparent that the average 
corrosion layer thickness decreased with the fly ash content increasing. According to the time-changing curves of corrosion rates shown in Fig. (4), we can know that the corrosion rates of all the samples had became steady, but the time of corrosion rate reaching stationary stage in OPC was earlier than the ones in FA10, FA20 and FA30, and the corrosion time added with the increase of fly ash replacement ratio.

Fig. (10a and b) present amplified 600 multiples SEM photographs of concrete-steel interface taken from OPC and FA20, Fig. (10c and d) illustrate the corresponding amplified 3000 multiples SEM photographs. It can be seen that the rust became more than before and the corrosion products conformation was changing from nubby to grained.

Fig. (11a-d) illustrate the sub-microstructures of reinforced-concrete interface taken from OPC, FA10, FA20 and FA30 after nine months corrosion. According to the timechanging curves of corrosion rates shown in Fig. (5), we can know that the corrosion rate is rising, and the corrosion layer thickness increases rapidly. It can be seen that the corrosion layers of all the samples were thicker, and the thickness of OPC, FA10, FA20 and FA30 were $420 \mu \mathrm{m}, 260 \mu \mathrm{m}, 200 \mu \mathrm{m}$ and $250 \mu \mathrm{m}$, respectively.

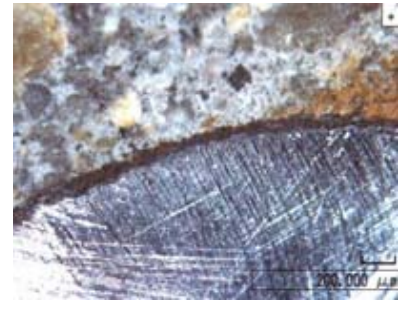

(a) OPC ( Test point 3)

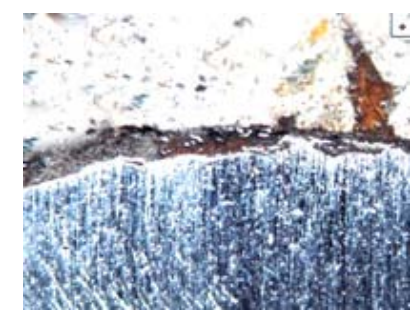

(b) FA10 (Test point 4)
Fig. (12a and b) present amplified 600 multiples SEM photographs of steel-concrete interface taken from OPC and FA20, Fig. (12c and d) illustrate the corresponding amplified 3000 multiples SEM photographs. The results show that OPC had appeared visible cracks and the corrosion productions were needle and stick-shape, however, FA20 had no visible cracks on the surface, the corrosion rate was still in the steady phase, and the corrosion layer thickness was increasing with a relatively slow speed.

\subsection{Mechanism}

An unclose-grained interface exists between steel and concrete, which provides some space for volume expansion of the corrosion productions. Because the volume of corrosion productions is bigger than the iron's, stress is produced after the corrosion productions reaches a certain quantity in the interface, the generated expansion stress makes the rust diffuse into concrete pores. With the increasing of rust in the interface, corrosion layer is gradually formed [12]. The whole process can be divided into three stages:

Fig. (9). Sub-microstructure of concrete-steel interface after five months corrosion.

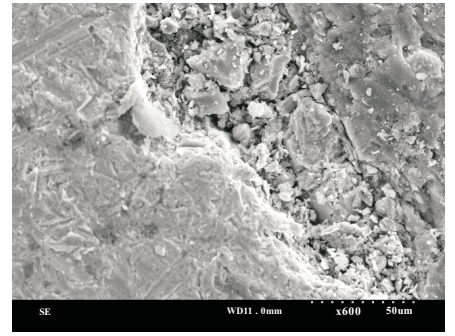

(a) OPC (600×)

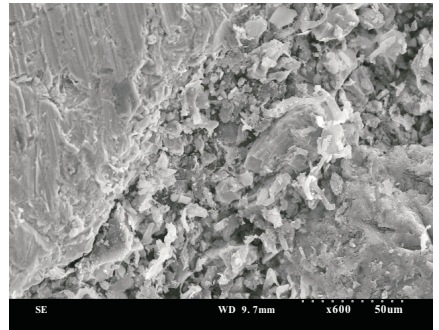

(b) FA20 $(600 \times)$

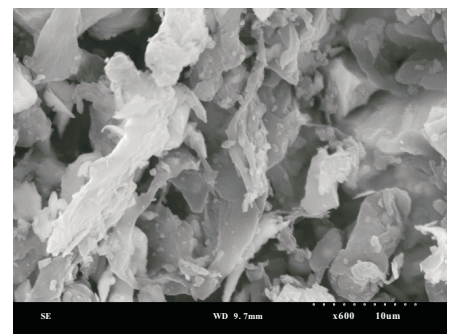

(c) OPC $(3000 \times)$

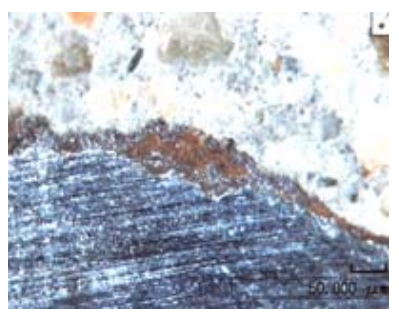

(d) FA30 (Test point 3)

Fig. (10). Microscopic structure of concrete-steel interface after five months corrosion.

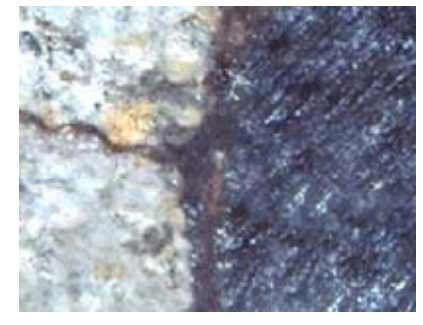

(a) OPC (Test point 3)

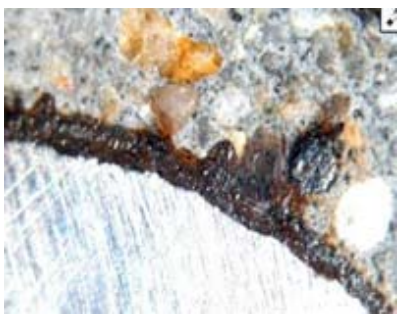

(b) FA10 (Test point 4)

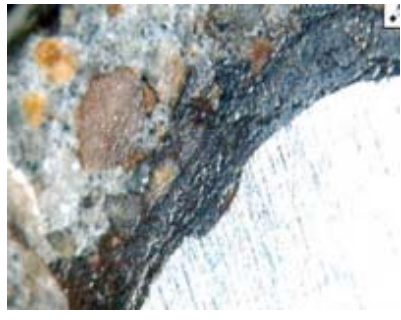

(c) FA20 (Test point 3)

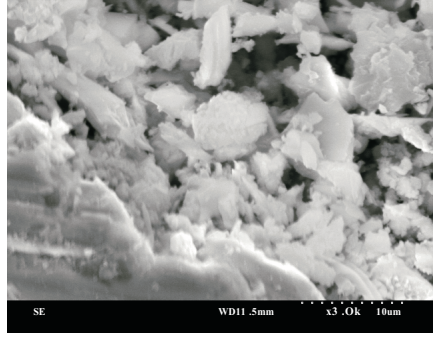

(d) FA20 (3000×)

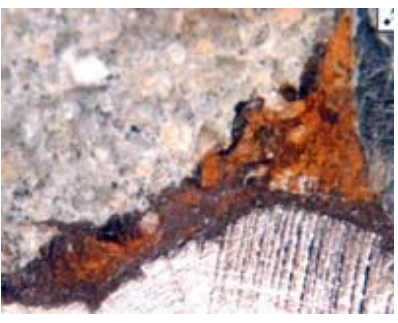

(d) FA30 (Test point 3)

Fig. (11). Sub-microstructure of concrete-steel interface after nine months corrosion. 


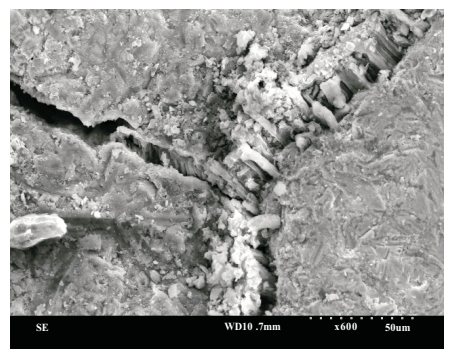

(a) $\mathrm{OPC}(600 \times)$

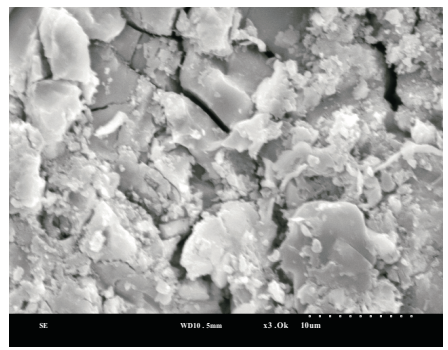

(b) FA20 $(600 \times)$

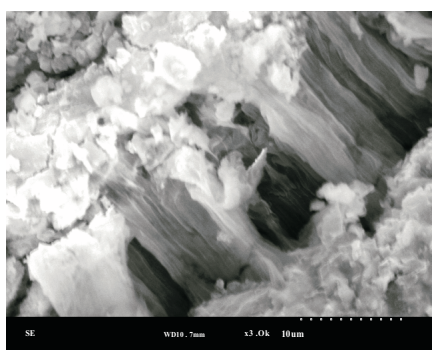

(c) OPC (3000×)

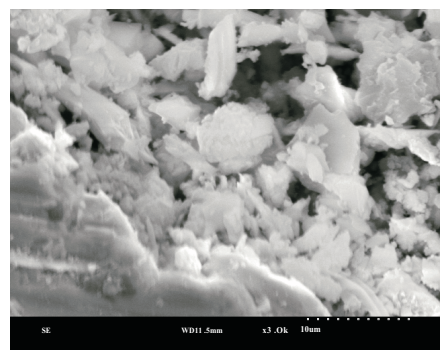

(d) FA20 (3000× $)$

Fig. (12). Microscopic structure of concrete-steel interface after nine months corrosion.

\section{(1) Corrosion rate decline stage}

Corrosion starting, fly ash has not participated in hydration reaction yet, but it reduces concrete porosity, making the interface between concrete and steel denser and oxygen into the concrete more difficult. With steel corrosion, the hydration products of cement and the corrosion products of rebar constantly spread into concrete pores around the rebar. With corrosion product volume increasing, it gradually fills steel/concrete interface and makes the interface more closegrained, so the corrosion rate declines. In this phase, the fly ash had not participated in the hydration reaction completely, so the downward trend of steel corrosion rates in concrete mixing with fly ash is gentler.

\section{(2) Corrosion rate longer stationary stage}

When rebar corrosion rate drops to a certain value, the corrosion rate is equivalent to ionic transmission rate, oxygen consumption rate of rust reaction and oxygen supply rate in external environment reaches equilibrium, corrosion rate trends to remain steady. In this phase, the fly ash has participated in the hydration reaction of cement, consuming part of the hydration productions of cement- $\mathrm{Ca}(\mathrm{OH})_{2}$, thus reduces the alkalinity of rebar surface. In addition, the pozzolanic reaction products of fly ash further fills with the gap of concrete, making the concrete denser, so water and oxygen diffuse into concrete more difficultly, it can offset the negative effect brought out by alkalinity decreasing of concrete. Therefore, the steel corrosion rate in concrete incorporated with fly ash is smaller than the one without fly ash, the replacement ratio is bigger, the effect is more apparent, this is consistent with the results in Literatures $[13,14]$.

\section{(3) Corrosion rate rising stage}

After the steel-concrete interface is full of corrosion products, the corrosion process continue developing, the corrosion product volume began to expand which brings a force in the interface. When the force reached tensile strength of concrete, the concrete cracks. Because the concrete incorporated with fly ash has better microstructure, the cracking time is later than the concrete without fly ash.

\section{CONCLUSION}

(1) With an increase in corrosion time, the concrete incorporated with $0 \%, 10 \%, 20 \%$ and $30 \%$ fly ash have similar steel corrosion rate variation trend: rapid decline in early stage-longer stationary phase in metaphase stage-rising in late stage. But in each phase, the rebar corrosion rate decreases with an increase in fly ash percentages.

(2) The addition of fly ash in concrete makes concrete-steel interface more close-grained and even which is beneficial for increasing the ability of concrete to resist steel corrosion, and the corrosion layer thickness is the smallest when the replacement ratio of fly ash is set to $20 \%$.

(3) The addition of fly ash in concrete has dual effects: (a) reducing concrete porosity and (b) improving the concrete-steel interface structure. The analytical results of present work show that cracking time of reinforced concrete incorporated with $10 \%, 20 \%$ and $30 \%$ low calcium fly ash is later than that of the concrete without fly ash, so it can be effectively used in structural concrete.

\section{ACKNOWLEDGMENTS}

The authors gratefully acknowledge the State Key Laboratory for Geomechanics \& Deep Underground Engineering for the use of laboratory facilities. This paper was supported by the National Nature Science Foundation of China (grant no. 50490270), the Ministry of Housing and Urban-Rural Development of China (grant no. 2010-K4-24), and the Engineering Project of High School Subject Innovation(grant no. B07028).

\section{CONFLICT OF INTEREST}

None Declared.

\section{REFERENCES}

[1] W. L. Jin and Y. X. Zhao, "The mechanism of corroded expansion force of reinforced concrete members", J. Hydraul Eng. Shuili Xuebao, vol. 7, pp. 57-62, 2001. (in Chinese)

[2] F. J. Molina, C. Alonso and C. Andrade, "Cover cracking as a function of rebar corrosion: part 2 numerical model", Mat. Struct., vol. 26, no. 9, pp. 532-548, 1993.

[3] M. F. Montemor, M. P. Cunha, M. G. Ferreira and A. M. Simões, "Corrosion behavior of rebars in fly ash mortar exposed to carbon dioxide and chlorides", Cement and Concrete Comp., vol. 24, no.1, pp. 45-53, February 2002.

[4] J. G. Cabrera, "Deterioration of concrete due to reinforcement steel corrosion", Cement and Concrete Comp., vol. 18, no. 1, pp. 47-59, February 1996.

[5] P. F. Marques, A. Costa, "Service life of RC structures: Carbonation induced corrosion. Prescriptive vs. performance-based methodologies", Construct. Build. Mat., vol. 24, no. 3, pp. 258-265, March 2010.

[6] Y. S. Ji, Y. S. Yuan, "Change characteristic and mechanism of rebar corrosion rate with time in concrete under constant climate", 
J. China Uni. Min. Technol., vol. 36, no. 2, pp. 153-158, March 2007. (in Chinese )

[7] H. Yu, Y. H. Zhang, Q. Wang, Q. Xu and Y. M. Deng, "Forecast model of steel corrosion rate of marine concrete", J. Build. Mat., vol. 12, no. 4, pp. 478-492, Apirl 2009.

[8] R. Siddique, "Performance characteristics of high-volume Class F fly ash concrete", Cement and Concrete Comp., vol. 34, no. 3, pp. 487-493, March 2004.

[9] C. S. Poon, L. Lam and Y. L. Wong, "A study on high strength concrete prepared with large volumes of low calcium fly ash", Cement and Concrete Res., vol. 30, no. 3, pp. 447-455, March 2000.

[10] L. H. Jiang, Z. Q. Liu and Y. Q. Ye, "Durability of concrete incorporating large volumes of low-quality fly ash", Cement and Concrete Res., vol. 34, no. 8, pp. 1467-1469, August 2004.
[11] V. Saraswathy, S. Muralidharan, K. Thangavel and S. Srinivasan, "Influence of activated fly ash on corrosion-resistance and strength of concrete", Cement and Concrete Comp., vol. 25, no. 7 , pp. 673-680, October 2003.

[12] Y. S. Yuan, Y. S. Ji and Y. J. Mou, "Propagation and model of distribution for corrosion of steel bars in concrete", China Civil Eng. J., vol. 40, no. 7, pp. 5-10, July 2007. (in Chinese )

[13] M. F. Montemor, A. M. P. Simões and M. M. Salta, "Effect of fly ash on concrete reinforcement corrosion studied by EIS", Cement and Concrete Comp., vol. 22, no. 3, pp. 175-185, June 2000.

[14] M. F. Montemor, A. M. P. Simões and M. M. Salta, "Corrosion behavior of steel bar embedded in fly ash concrete", Corrosion Sci., vol. 48, no. 7, pp. 1733-1745, July 2006.

Received: March 17, 2011

Revised: August 03, 2011

Accepted: October 04, 2011

(C) Xu et al.; Licensee Bentham Open.

This is an open access article licensed under the terms of the Creative Commons Attribution Non-Commercial License

(http://creativecommons.org/licenses/_by-nc/3.0/) which permits unrestricted, non-commercial use, distribution and reproduction in any medium, provided the work is properly cited. 